\title{
An improved method for determining Brooks-Corey model parameters from horizontal absorption
}

\author{
DongHao Ma ${ }^{\text {a }}$, JiaBao Zhang ${ }^{\mathrm{a}, *}$, JianBin Lai ${ }^{\mathrm{b}}$, Quanjiu Wang ${ }^{\mathrm{c}}$

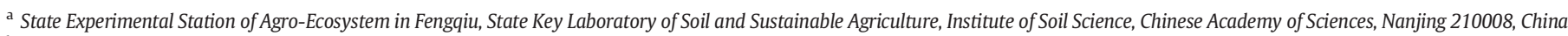 \\ b Institute of Geographical Sciences and Natural Resources Research, Chinese Academy of Sciences, Beijing 100101, China \\ c Institute of Water Resources Research, Xi'an University of Technology, Xi'an, Shannxi 710048, China
}

\section{A R T I C L E I N F O}

\section{Article history:}

Received 3 April 2015

Received in revised form 1 September 2015

Accepted 14 September 2015

Available online 29 September 2015

\section{Keywords:}

Soil hydraulic properties

Brooks-Corey model

Horizontal absorption

Approximate solution

\begin{abstract}
A B S T R A C T
Low-cost, simple, rapid and accurate approaches for measuring soil hydraulic properties are of great importance in the application of hydrologic models of the vadose zone. A recently proposed method of constant-saturation absorption (MCSA) for determining Brooks-Corey (BC) model parameters is promising. However, this method has not been tested using experimental data. In this paper, measured soil-water diffusivity or soil-water retention curves (SWRCs) of 20 soil samples were used to test the reliability of MCSA. The results indicate that MCSA consistently estimated soil-water diffusivities by the Bruce and Klute method, but it substantially overestimated air-entry suctions $\left(h_{\mathrm{d}}\right)$ and thereby soil suction. A new method (MCPA) is proposed herein to overcome the problems associated with MCSA. Using the improved method, estimated SWRCs are consistent with observation. With the estimated soil hydraulic parameters, HYDRUS-1D generated very accurate simulations of the cumulative absorption curves. Compared with direct or other indirect methods, MCPA is a more accurate, low-cost, and simple method, and it is especially useful for rapid determination of SWRC for soil-water movement simulations. However, if unsaturated soil-water diffusivity is of greater concern, our results also indicate that MCSA more accurately predicts this quantity and thus should be preferred.
\end{abstract}

(c) 2015 Elsevier B.V. All rights reserved.

\section{Introduction}

The vadose zone is critical to controlling the hydrologic cycle and solute transport. Quantitative prediction and assessment of the behaviors of water flow and solute transport in the vadose zone are very important for making appropriate measurements for improving the usage efficiency of water resources and fertilizers and to protect groundwater from contamination. Numerical solutions are successfully and commonly used to simulate water flow and solute transport in unsaturated soils. Soil hydraulic properties (soil-water retention curves or SWRCs, hydraulic conductivity, or water diffusivity) are required inputs for hydrologic simulations. Normally, one of the main difficulties in the application of hydrologic models is the rapid acquisition of accurate soil hydraulic properties at low cost. In the last several decades, direct and indirect methods have been developed to determine those properties (Dane and Puckett, 1992; Durner and Lipsius, 2005; van Genuchten, 1992). Direct methods measure soil hydraulic properties according to their basic definitions, whereas indirect methods estimate them from

\footnotetext{
* Corresponding author.

E-mail addresses: dhma@issas.ac.cn (D.H. Ma), jbzhang@issas.ac.cn (J.B. Zhang), laijianbin@igsnrr.ac.cn (J.B. Lai), wquanjiu@163.com (Q.J. Wang).
}

other soil properties (e.g., soil particle size distribution, soil organic content, or soil-water movement processes) that are readily measured. More details and reviews of these methods are in Shao and Horton (1998) and van Dam et al. (1992). Direct methods are time consuming and expensive, and measurable data ranges are typically limited. Among the indirect methods, pedotransfer functions are localized and appropriate for simulations at large scales rather than at specific sites. Numerical inversion has difficulties such as failure of solution convergence and the uniqueness of estimated parameters (Shao and Horton, 1998). These problems have restricted the practical use of the methods. Thus, simple, rapid, accurate and low-cost methods for determining soil hydraulic model parameters remain scarce and continue to be one of the main topics of soil physical research (Londra and Valiantzas, 2011; Ma et al., 2009; Shao and Horton, 1996, 1998; Valiantzas and Londra, 2008, 2012; Wang et al., 2002, 2004).

Recently, a promising indirect method (Londra and Valiantzas, 2011; Ma et al., 2009; Shao and Horton, 1998; Wang et al., 2002) was proposed based on approximate solutions to the Richards equation (Richards, 1931) with specific soil hydraulic property functions, such as the Brooks-Corey (BC) model (Brooks and Corey, 1964) and the van Genuchten (VG) model (van Genuchten, 1980). The concept of an integral or analytical method was first proposed by Shao and Horton (1998) for estimating VG model parameters, and it was further 
developed by Wang et al. (2002) and Ma et al. (2009, 2010) to determine BC model parameters from horizontal absorption. Using the means, VG or BC model parameters can be estimated by simple relation equations of saturated hydraulic conductivity, sorptivity, characteristic length of the wetted zone, and initial, residual and saturated soil moisture contents. These variables are easy to determine by conventional approaches and horizontal absorption experiments. Compared with direct methods and other indirect methods, the analytical method is simple, rapid, and low-cost.

However, some problems remain to be solved for the analytical or horizontal absorption methods. For example, the first-order approximation of the VG model used by Shao and Horton (1998) only applies to the near-saturation range of SWRCs. The assumption of soil matric suction distribution made by Wang et al. (2002) may be valid for moderate-texture soils but not for heavy-texture or light-texture soils. The method proposed by Ma et al. $(2009,2010)$ extended the applicable texture range of the horizontal absorption approach, but the theory has not been validated by measured SWRCs. Moreover, Wang et al. (2002) and Ma et al. (2009, 2010) tested their methods using only the given soil hydraulic parameters and constant-saturation absorption processes simulated by the HYDRUS-1D software (Šimůnek et al., 2005). Because effective water saturation does not vary with soil suction when the latter is smaller than air-entry suction in the BC model, the constantsaturation inlet boundary used in the approximate solutions of Wang et al. (2002) and Ma et al. (2009) was different from the one in actual horizontal absorption experiments. Although effective water saturations at both inlet boundaries were equal to one, the water pressure head at the inlet $\left(h_{\mathrm{p}}\right)$ was equal to the air-entry pressure head $\left(-h_{\mathrm{d}}\right)$ in the solutions of Wang et al. (2002) and Ma et al. (2009), whereas

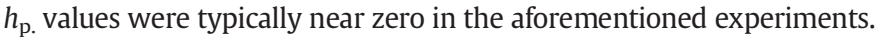
As a result, the air-entry suction of the $\mathrm{BC}$ model may be overestimated in Ma et al. (2009), in which observed horizontal absorption data were used without considering this difference of water pressure heads at the inlet boundaries.

Therefore, the objective of the research was to derive an improved expression for more accurate estimation of air-entry suction. The expression was verified with horizontal absorption experiments for twenty soils, and the estimated soil-water retention curves and soil-water diffusivity curves were compared with the measured values.

\section{Theory}

The Brooks-Corey model (Brooks and Corey, 1964) describing soil hydraulic properties is the soil-water retention curve

$S(h)= \begin{cases}\frac{\theta-\theta_{\mathrm{r}}}{\theta_{\mathrm{s}}-\theta_{\mathrm{r}}}=\left(\frac{h_{\mathrm{d}}}{h}\right)^{n} & h>h_{\mathrm{d}} \\ 1 & h \leq h_{\mathrm{d}}\end{cases}$

and the soil hydraulic conductivity curve

$K(h)= \begin{cases}K_{\mathrm{s}}\left(\frac{h_{\mathrm{d}}}{h}\right)^{m}=K_{\mathrm{s}} S^{l+1+2 / n} & h>h_{\mathrm{d}} \\ K_{\mathrm{s}} & h \leq h_{\mathrm{d}}\end{cases}$

where $\theta$ is volumetric soil-water content $\left(\mathrm{cm}^{3} \mathrm{~cm}^{-3}\right), \theta_{\mathrm{r}}$ and $\theta_{\mathrm{s}}$ are residual and saturated water contents $\left(\mathrm{cm}^{3} \mathrm{~cm}^{-3}\right)$, respectively, $S$ is effective water saturation, $h$ is soil matric suction $(\mathrm{cm}), K$ is hydraulic conductivity $\left(\mathrm{cm} \mathrm{min}^{-1}\right), K_{\mathrm{s}}$ is saturated hydraulic conductivity $\left(\mathrm{cm} \mathrm{min}{ }^{-1}\right), n$ is a constant related to the shape of SWRC, and $m=$ $(l+1) n+2$, where $l$ is the soil pore tortuosity factor, for which $l=2$ is typically used.

Soil-water diffusivity can be obtained from $S(h)$ and $K(h)$ by the following relationship.

$D(S)=-K \frac{d h}{d \theta}=D_{S} S^{L}$ where $D$ is soil-water diffusivity $\left(\mathrm{cm}^{2} \mathrm{~min}^{-1}\right), D_{\mathrm{s}}$ is soil-water diffusivity at saturation $\left(\mathrm{cm}^{2} \mathrm{~min}^{-1}\right)$, and $L$ is a shape coefficient of the powerfunction soil-water diffusivity curve.

\subsection{Method based on constant-saturation absorption (MCSA)}

The method of Ma et al. (2009, 2010) was derived based on an approximate analytical solution to the Richards equation (Richards, 1931) for one-dimensional horizontal absorption into homogeneous soils, with initially uniform moisture contents under constantsaturation boundary conditions. For differentiating from the method below, we call this the method of constant-saturation absorption (MCSA). The complete expressions in MCSA (Ma et al., 2009) for estimating soil hydraulic parameters are.

$n=\frac{a}{1-2 a}$

$h_{\mathrm{d}}=\frac{1+a}{(1-2 a)\left(1-S_{\mathrm{i}}^{1+1 / a}\right)} \cdot \frac{s^{2}}{2 K_{\mathrm{s}}\left(\theta_{\mathrm{s}}-\theta_{\mathrm{i}}\right)}$,

$L=\frac{1}{a}$,

$D_{\mathrm{s}}=\frac{1+a}{a\left(1-S_{\mathrm{i}}^{1+1 / a}\right)} \cdot \frac{s^{2}}{2\left(\theta_{\mathrm{s}}-\theta_{\mathrm{i}}\right)\left(\theta_{\mathrm{s}}-\theta_{\mathrm{r}}\right)}$,

where $\theta_{\mathrm{i}}$ is the initial soil-water content $\left(\mathrm{cm}^{3} \mathrm{~cm}^{-3}\right), S_{\mathrm{i}}$ is the initial effective water saturation, $A$ is the average increase in soil-water content in the wet zone $\left(\mathrm{cm}^{3} \mathrm{~cm}^{-3}\right)$ and $s$ is the sorptivity $\left(\mathrm{cm} \mathrm{min}^{-0.5}\right)$, and $a$ and $b$ are constants for a specific soil with a specific initial moisture content which can be determined from the formulas below for initially dry soils.

$a \approx \frac{\theta_{\mathrm{s}}-\theta_{\mathrm{i}}-A}{\theta_{\mathrm{i}}-\theta_{\mathrm{r}}+A}, \quad b=1-S_{\mathrm{i}}^{\frac{1}{a}}$

For determining BC model parameters, apart from the values of $\theta_{\mathrm{i}}, \theta_{\mathrm{r}}$ and $\theta_{\mathrm{s}}$, only a conventional constant water head experiment (for measuring $K_{\mathrm{s}}$ ) and simple horizontal absorption experiment with initially dry soils were required. The parameter $d$ is defined as the characteristic length of the wetting zone $\left(\mathrm{cm} \mathrm{min}^{-0.5}\right) . A, d$ and $s$ can be obtained by fitting Eqs. (9) and (10) to the observed wetting front advance and cumulative infiltration volume versus time during the horizontal absorption experiments.

$x_{\mathrm{f}}=d \cdot t^{0.5}$,

$I=s \cdot t^{0.5}=A \cdot x_{\mathrm{f}}$

where $I$ is cumulative absorption at the water inlet $(\mathrm{cm}), x_{\mathrm{f}}$ is the wetting front advance $(\mathrm{cm}), t$ is infiltration time $(\min )$ and $A=s / d$. Then, $a$ can be calculated by Eq. (8), and the BC model parameters $\left(n, h_{\mathrm{d}}, L\right.$ and $D_{\mathrm{s}}$ ) are subsequently estimated by Eqs. (4) through (7).

\subsection{Method based on constant pressure head absorption (MCPA)}

As discussed above, for actual horizontal absorption experiments, the saturated inlet boundary typically corresponds to $h_{\mathrm{p} \text {. }} \approx 0$, whereas $h_{\mathrm{p} .}=-h_{\mathrm{d}}$ is used in the derivation of MCSA. Thus, to derive a more accurate expression, it is necessary to estimate $h_{\mathrm{d}}$ based on the inlet boundary of the aforesaid experiments. In contrast with MCSA, the new expression, called MCPA, was derived based on constant pressure head absorption. 
The Buckingham-Darcy law can be expressed as.

$J_{\mathrm{w}}=-K(h) \frac{d h}{d x}$

where $x$ is the distance from the water inlet $(\mathrm{cm})$, and $J_{\mathrm{w}}$ is soil-water flux $\left(\mathrm{cm} \mathrm{min}{ }^{-1}\right)$.

Rearranging Eq. (11) and integrating its left side from 0 to $x_{\mathrm{f}}$ for $x$ and its right side from $h_{\mathrm{p}}$ to $h_{\mathrm{i}}$ for $h$, we obtain.

$\int_{0}^{x_{\mathrm{f}}} J_{\mathrm{w}} d x=\int_{h_{\mathrm{p}}}^{h_{\mathrm{i}}} K d h=h_{\mathrm{p}} K_{\mathrm{s}}+h_{\mathrm{d}} K_{\mathrm{s}}+\int_{h_{\mathrm{d}}}^{h_{\mathrm{i}}} K d h$,

where $h_{\mathrm{i}}$ is the soil suction (cm) corresponding to the initial soil moisture content.

According to Philip (1973), $J_{\mathrm{w}}$ can be estimated only with the soilwater flux at the inlet $\left(J_{\mathrm{w} 0}\right)$ and the relative soil-water saturation, that is,

$J_{\mathrm{w}}=\frac{\theta-\theta_{\mathrm{i}}}{\theta_{\mathrm{s}}-\theta_{\mathrm{i}}} J_{\mathrm{w} 0}$

The equation derived by Ma et al. (2009) for describing the soilwater distribution along the soil profile is.

$S=\left(1-b \frac{x}{x_{\mathrm{f}}}\right)^{a}$

After substituting Eqs. (13) and (14) into the left side of Eq. (12) and submituting Eq. (2) into the right side, and then integrating, we get.

$J_{\mathrm{w} 0}=\frac{b(a+1)\left(1-S_{\mathrm{i}}\right)}{1-(1+a b) S_{\mathrm{i}}} K_{\mathrm{s}}\left(\left(\frac{3 n+2-S_{\mathrm{i}}^{3+1 / n}}{3 n+1}\right) h_{\mathrm{d}}+h_{\mathrm{p}}\right) \frac{1}{x_{\mathrm{f}}}$.

Considering Eq. [25] in Ma et al. (2009) and Eq. (10),

$A=\left(\theta_{\mathrm{s}}-\theta_{\mathrm{r}}\right) \frac{1-(1+a b) S_{\mathrm{i}}}{(a+1) b}$,

$J_{\mathrm{w} 0}=\frac{d I}{d t}=\frac{s^{2}}{2 I}=\frac{s^{2}}{2 A} \frac{1}{x_{\mathrm{f}}}$.
After substituting Eq. (16) into Eq. (17), comparing Eq. (17) with Eq. (15) yields.

$s^{2}=2 K_{\mathrm{s}}\left(\theta_{\mathrm{s}}-\theta_{\mathrm{i}}\right)\left(\left(\frac{3 n+2-S_{\mathrm{i}}^{3+1 / n}}{3 n+1}\right) h_{\mathrm{d}}+h_{\mathrm{p}}\right)$.

The form of Eq. (18) is the same as in other studies (Haverkamp et al., 1990; Morelsey and Khanji, 1974; Philip, 1958; Stewart et al., 2013; White and Sully, 1987) in which the first term in the second bracket on the right side of the equation was replaced by a variable representing the achievement of "capillary potential." From Eq. (18), we obtain a new formula to calculate $h_{\mathrm{d}}$, with $n$ replaced by $a$ using the relationship in Eq. (4):

$h_{\mathrm{d}}=\frac{1+a}{2-a-(1-2 a) S_{\mathrm{i}}^{1+1 / a}}\left(\frac{s^{2}}{2 K_{\mathrm{s}}\left(\theta_{\mathrm{s}}-\theta_{\mathrm{i}}\right)}-h_{\mathrm{p}}\right)$

Correspondingly, a new expression for estimating $D_{\mathrm{s}}$ is deduced by substituting Eqs. (4) and (19) into Eq. [15] in Ma et al. (2009):

$D_{\mathrm{s}}=\frac{1+a}{a\left((2-a) /(1-2 a)-S_{\mathrm{i}}^{1+1 / a}\right)\left(\theta_{\mathrm{s}}-\theta_{\mathrm{r}}\right)} \cdot\left(\frac{s^{2}}{2\left(\theta_{\mathrm{s}}-\theta_{\mathrm{i}}\right)}-K_{\mathrm{s}} h_{\mathrm{p}}\right)$.

Clearly, Eq. (19) transforms into Eqs. (5) and (20) transforms into Eq. (6) when $h_{\mathrm{p} .}=-h_{\mathrm{d}}$.

\section{Materials and methods}

Twenty soil samples (Table 1) were used to test the proposed methods. The first nine soils were Lizhuang loam soil (17.6\% clay, 39.1\% silt, and 43.3\% sand) from Henan Province in China, Ansai sandy loam ( $8.5 \%$ clay, $37.5 \%$ silt, and $54.0 \%$ sand), Yulin sand (3.7\% clay, $7.8 \%$ silt, and $88.5 \%$ sand), Suide sandy loam (9.6\% clay, $34.6 \%$ silt, and $55.9 \%$ sand), and five samples of Shenmu sand ( $0.2 \%$ clay, $13.4 \%$ silt, and $86.3 \%$ sand $)$ with different rock fragment mass contents $\left(R_{\mathrm{m}}=0\right.$, $10 \%, 20 \%, 30 \%$ and $40 \%$, respectively) from Shaanxi Province in China. The other 11 soils were Manawatu fine sandy loam (Clothier and Scotter, 1982), Hagener sand (Selim et al., 1970), Hayden sandy loam

Table 1

Basic physical properties of the soils.

\begin{tabular}{|c|c|c|c|c|c|c|c|}
\hline \multirow[t]{2}{*}{ ID } & \multirow[t]{2}{*}{ Soil } & \multirow{2}{*}{$\frac{\mathrm{BD}}{\mathrm{g} \mathrm{cm}^{-3}}$} & $\theta_{\mathrm{s}}$ & $\theta_{\mathrm{i}}$ & \multirow{2}{*}{$\frac{K_{\mathrm{s}}}{\mathrm{cm} \mathrm{min}^{-1}}$} & \multirow{2}{*}{\multicolumn{2}{|c|}{$\frac{s}{\mathrm{~cm} \mathrm{~min}}-0.5$}} \\
\hline & & & \multicolumn{2}{|c|}{$\mathrm{cm}^{3} \mathrm{~cm}^{-3}$} & & & \\
\hline 1 & Lizhuang loam & 1.4 & 0.45 & 0.028 & 0.019 & 0.51 & 1.42 \\
\hline 2 & Ansai sandy loam & 1.35 & 0.48 & 0.019 & 0.0207 & 0.51 & 1.32 \\
\hline 3 & Yulin sand & 1.7 & 0.38 & 0.014 & 0.0484 & 0.75 & 2.54 \\
\hline 4 & Suide sandy loam & 1.4 & 0.472 & 0.018 & 0.017 & 0.51 & 1.29 \\
\hline 5 & Shenmu sand $\left(R_{\mathrm{m}}=0\right)$ & 1.50 & 0.42 & 0.0173 & 0.0485 & 1.18 & 3.69 \\
\hline 6 & Shenmu sand $\left(R_{\mathrm{m}}=10 \%\right)$ & 1.53 & 0.408 & 0.0165 & 0.0520 & 1.04 & 3.40 \\
\hline 7 & Shenmu sand $\left(R_{\mathrm{m}}=20 \%\right)$ & 1.57 & 0.395 & 0.0158 & 0.0425 & 0.98 & 3.30 \\
\hline 8 & Shenmu sand $\left(R_{\mathrm{m}}=30 \%\right)$ & 1.61 & 0.382 & 0.015 & 0.0392 & 0.90 & 3.11 \\
\hline 9 & Shenmu sand $\left(R_{\mathrm{m}}=40 \%\right)$ & 1.65 & 0.368 & 0.0142 & 0.0455 & 0.91 & 3.22 \\
\hline 10 & Manawatu sandy loam ${ }^{\mathrm{b}}$ & 1.3 & 0.440 & 0.08 & 0.0672 & 1.14 & 4.69 \\
\hline 11 & Hagener sand ${ }^{\mathrm{a}}$ & - & 0.37 & 0.054 & - & 1.49 & 5.87 \\
\hline 12 & Hayden sandy loam ${ }^{\mathrm{a}}$ & - & 0.51 & 0.0146 & - & 0.78 & 1.908 \\
\hline 13 & Manawatu fine sandy loam ${ }^{a}$ & - & 0.36 & 0.08 & - & 1.138 & 4.49 \\
\hline 14 & Adelanto loam ${ }^{\mathrm{a}}$ & - & 0.387 & 0.038 & - & 0.333 & 1.01 \\
\hline 15 & Edina silt loam ${ }^{\mathrm{a}}$ & - & 0.5 & 0.056 & - & 0.76 & 2.0139 \\
\hline 16 & Nicollet sandy clay loam ${ }^{a}$ & - & 0.364 & 0.038 & - & 0.404 & 1.348 \\
\hline 17 & Fayette silty clay loam ${ }^{\mathrm{a}}$ & - & 0.448 & 0.048 & - & 0.337 & 0.96 \\
\hline 18 & Panoche clay loam ${ }^{\mathrm{a}}$ & - & 0.443 & 0.048 & - & 0.73 & 2.129 \\
\hline 19 & Pine silty clay ${ }^{\mathrm{a}}$ & - & 0.463 & 0.05 & - & 0.294 & 0.75 \\
\hline 20 & Yolo clay $^{\mathrm{a}}$ & - & 0.49 & 0.04 & - & 0.131 & 0.36 \\
\hline
\end{tabular}

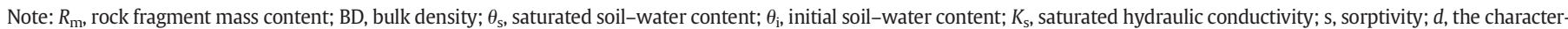
istic length of the wetting zone.

a Data from Evangelides et al. (2010).

b Data from Shao and Horton (1998). 
(Whisler et al., 1968), Manawatu fine sandy loam (Clothier et al., 1983), Adelanto loam (Jackson, 1963), Edina silt loam (Selim et al., 1970), Nicollet sandy clay loam (McBride and Horton, 1985), Fayette silty clay loam (Mcbride and Horton, 1985), Panoche clay loam (Reichardt et al., 1972), Pine silty clay (Jackson, 1963), and Yolo clay (Nofziger, 1978).

Basic properties of the first nine soils were measured and are shown in Table 1. The sampled soils were air-dried and sieved. Particles of $<2 \mathrm{~mm}$ diameter were used for the experiments. Particle-size was analyzed using the pipette method (Gee and Or, 2002). Saturated water contents were obtained using measured water contents (by mass) at saturation with the soil bulk densities in Table 1. Saturated hydraulic conductivities of soils No. 1-4 (see Table 1) were determined using a constant-head method for soil columns filled with the same bulk densities (Klute and Dirksen, 1986). For Shenmu sand, the rock fragments $(10-20 \mathrm{~mm})$ used were separated from fine earth $(<2 \mathrm{~mm})$ by sieving. The bulk density and the porosity of the fragments were $1.94 \mathrm{~g} \mathrm{~cm}^{-3}$ and $0.27 \mathrm{~cm}^{3} \mathrm{~cm}^{-3}$, respectively. The particle density of the fine earth was $2.59 \mathrm{~g} \mathrm{~cm}^{-3}$. The saturated water content of the fine earth was $0.42 \mathrm{~cm}^{3} \mathrm{~cm}^{-3}$ at a bulk density of $1.5 \mathrm{~g} \mathrm{~cm}^{-3}$. More details on the properties of stony soils and the preparation of soil samples are in Ma and Shao (2008) and Ma et al. (2010).

Traditional horizontal absorption experiments (Bruce and Klute, 1956) (Fig. 1) of with the first nine soils were performed for determining sorptivity $(s)$ and the characteristic length of the wetting zone $(d)$, as well as soil-water diffusivity $(D-\theta)$. Air-dried soils were each uniformly packed into sectioned Plexiglas columns (length $50 \mathrm{~cm}$ and inner diameter $3 \mathrm{~cm}$ for Lizhuang soil; length $60 \mathrm{~cm}$ and inner diameter $9 \mathrm{~cm}$ for Ansai, Yulin and Suide soils) with controlled bulk densities (Table 1). To fill the columns as uniformly as possible and avoid particle segregation, each $10-\mathrm{cm}$ layer of soil was weighed separately before being packed into the columns. Before filling a new layer, the packed soil surface was treated using a brush to avoid soil stratification. For the Shenmu sand, weights of rock fragments and fine earth were calculated according to the total bulk densities in Table 1. Similarly, the rock fragments and fine earth in each 10-cm layer were weighed separately and mixed in a single container before packing into the columns (length $50 \mathrm{~cm}$, inner diameter $11 \mathrm{~cm}$ ). Water was supplied with a constant pressure head $\left(h_{\mathrm{p}}=0\right)$ by a Marriott bottle. Cumulative absorption and wetting front advance versus time were recorded during the experiments. After the absorption experiments, saturated hydraulic conductivities of Shenmu sandy soils were measured with the same columns, using a constant head method (Klute and Dirksen, 1986).

The soil-water diffusivity curves were calculated from measured soil moisture profiles using the method of Bruce and Klute (1956). These

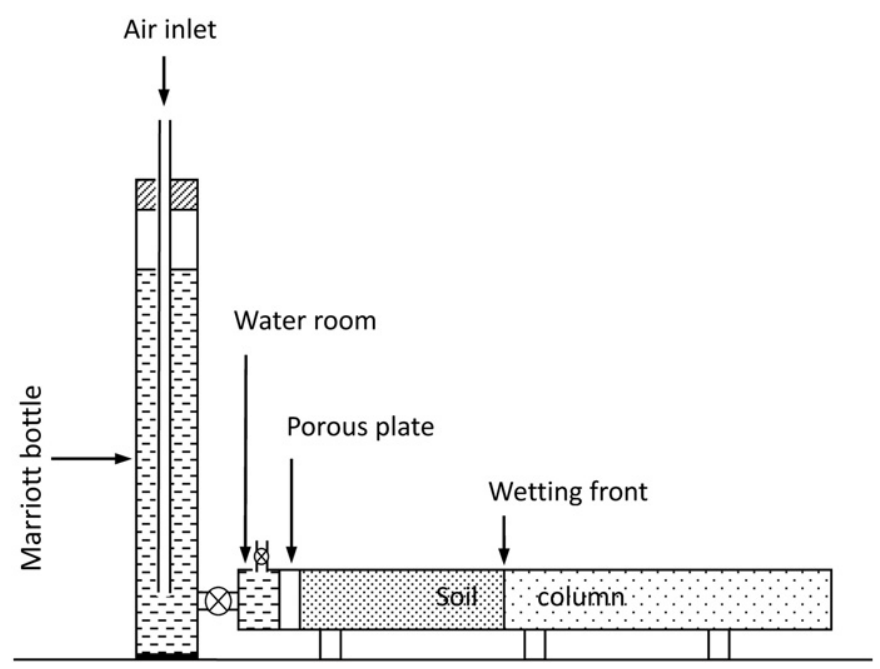

Fig. 1. Schematic diagram of experimental setup for horizontal absorption. profiles for Ansai, Yulin and Suide soils were measured by a $\gamma$ radiation attenuation method (Wang et al., 2004) during horizontal absorption. For Lizhuang soil, water contents in the profile were measured by an oven-drying method, by sectioning the soil column into 2.5 - $\mathrm{cm}$ portions at the end of the absorption experiment. Soil-water diffusivity curves of the five Shenmu sandy soils were not determined because no measured soil moisture profile was available. Observed soil moisture profile data of the last 10 soils were taken from Shao and Horton (1998).

SWRCs of the first nine soils were measured with the setup shown in Fig. 2. Soil matric potential was measured by a tensiometer inserted into the center of a Plexiglas soil box (height $11 \mathrm{~cm}$, inner diameter $14 \mathrm{~cm}$ ). For obtaining initial soil suction below the maximum range of this tensiometer, soils with a certain water content were prepared by mixing air-dried soils with the corresponding amount of water in a container, which was then covered with plastic film and left overnight for soilwater redistribution. Using the same method as in the horizontal absorption experiments, the prepared soils were uniformly packed into the soil boxes, with the same bulk densities as in Table 1. A tensiometer was inserted during soil filling, with the ceramic head at the center of the box. The total water quantity required for the soils in the box to reach saturation was calculated from the initial and saturated moisture contents as well as the total volume. Wetting curves of the SWRCs were measured by spraying the required water gradually onto the soil surface. After each addition of water, the box was covered and sealed for water redistribution. Soil matric suction was recorded by the tensiometer once the reading no longer varied and soil-water potential equilibrium was reached. At the same time, the soil box was weighed to calculate the corresponding soil-water content by the water balance approach. Then, the cover was opened for the next water addition and measurement. The process was repeated until the soil reached saturation. In contrast, drying curves of the SWRCs were measured by stepwise evaporation of soil-water in the box. The measurements began just after the wetting processes terminated. First, the cover and bottom of the box were left open for 1 or 2 days to permit evaporation. Then, the box was covered and sealed for several days for water redistribution. Using the same methods as above, soil matric potential and water content were measured when the equilibrium state was reached. The process was repeated until the tensiometer reached its upper limit. SWRC data of the 10th soil were from Shao and Horton (1998).

The experiments and procedures required to determine the $\mathrm{BC}$ model parameters are very simple for both MCSA and MCPA. Assuming $\theta_{\mathrm{r}}=0$ for the convenience of practical applications, apart from $\theta_{\mathrm{i}}$ and $\theta_{\mathrm{s}}$,

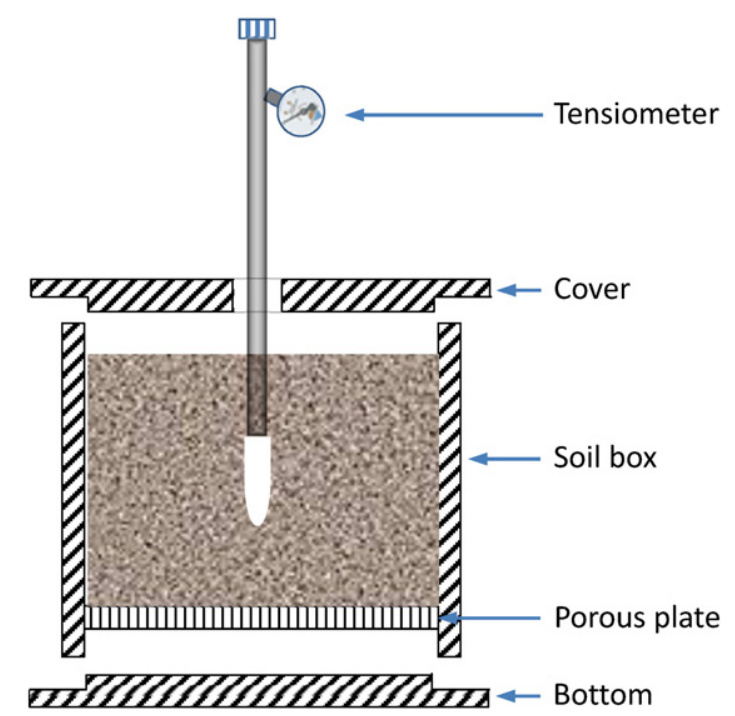

Fig. 2. Schematic diagram of experimental setup for soil-water retention curve measurements. 
Table 2

Estimated soil hydraulic properties of the twenty soils.

\begin{tabular}{|c|c|c|c|c|c|c|c|c|c|c|}
\hline \multirow{3}{*}{ Soil } & \multirow{3}{*}{$L$} & \multirow{3}{*}{$n$} & \multicolumn{4}{|l|}{ MCSA } & \multicolumn{4}{|l|}{ МСРА } \\
\hline & & & \multirow{2}{*}{$\frac{D_{s} \dagger}{\mathrm{cm}^{2} \min ^{-1}}$} & \multirow{2}{*}{$\frac{h_{\mathrm{d}} \dagger}{\mathrm{cm}}$} & \multirow{2}{*}{$\frac{\mathrm{RMSE}^{\mathrm{W}}}{\mathrm{cm}^{3} \mathrm{~cm}^{-3}}$} & \multirow[t]{2}{*}{$\mathrm{RMSE}^{\mathrm{D}}$} & \multirow{2}{*}{$\frac{D_{\mathrm{s}} \dagger}{\mathrm{cm}^{2} \min ^{-1}}$} & \multirow{2}{*}{$\frac{h_{\mathrm{d}} \dagger}{\mathrm{cm}}$} & $\mathrm{RMSE}^{\mathrm{W}}$ & $\mathrm{RMSE}^{\mathrm{D}}$ \\
\hline & & & & & & & & & \multicolumn{2}{|l|}{$\mathrm{cm}^{3} \mathrm{~cm}^{-3}$} \\
\hline 1 & 5.8 & 0.263 & 4.81 & 29 & 0.09 & - & 1.80 & 10 & 0.02 & - \\
\hline 2 & 5.5 & 0.284 & 4.25 & 25 & 0.04 & 0.05 & 1.31 & 8 & 0.07 & 0.10 \\
\hline 3 & 4.2 & 0.449 & 10.50 & 37 & 0.11 & 0.08 & 3.33 & 11 & 0.01 & 0.03 \\
\hline 4 & 6.4 & 0.228 & 4.42 & 28 & 0.06 & 0.05 & 1.88 & 10 & 0.04 & 0.07 \\
\hline 5 & 4.0 & 0.499 & 20.69 & 89 & 0.16 & 0.11 & 6.04 & 25 & 0.04 & 0.02 \\
\hline 6 & 3.7 & 0.582 & 16.03 & 73 & 0.13 & 0.07 & 4.36 & 19 & 0.02 & 0.07 \\
\hline 7 & 3.8 & 0.569 & 15.34 & 81 & 0.13 & 0.07 & 4.20 & 22 & 0.02 & 0.05 \\
\hline 8 & 3.8 & 0.549 & 13.93 & 75 & 0.11 & 0.04 & 3.99 & 20 & 0.02 & 0.07 \\
\hline 9 & 4.2 & 0.451 & 16.79 & 61 & 0.09 & 0.04 & 4.86 & 18 & 0.01 & 0.07 \\
\hline 10 & 2.8 & 1.316 & 16.74 & 133 & 0.17 & - & 2.60 & 22 & 0.04 & - \\
\hline 11 & 5.0 & 0.339 & 58.53 & - & - & - & 18.73 & - & - & - \\
\hline 12 & 4.9 & 0.346 & 7.13 & - & - & - & 2.33 & - & - & - \\
\hline 13 & 12.6 & 0.095 & 89.14 & - & - & - & 38.14 & - & - & - \\
\hline 14 & 19.1 & 0.059 & 8.28 & - & - & - & 3.78 & - & - & - \\
\hline 15 & 6.5 & 0.222 & 9.96 & - & - & - & 3.66 & - & - & - \\
\hline 16 & 12.8 & 0.092 & 9.61 & - & - & - & 4.18 & - & - & - \\
\hline 17 & 8.2 & 0.163 & 2.94 & - & - & - & 1.17 & - & - & - \\
\hline 18 & 7.5 & 0.182 & 13.16 & - & - & - & 5.08 & - & - & - \\
\hline 19 & 21.0 & 0.053 & 5.01 & - & - & - & 2.31 & - & - & - \\
\hline 20 & 4.7 & 0.372 & 0.23 & - & - & - & 0.07 & - & - & - \\
\hline
\end{tabular}

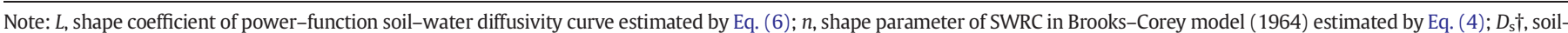

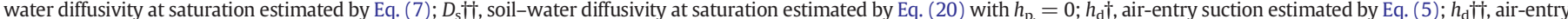

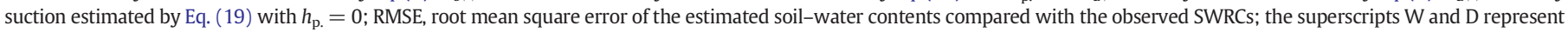
wetting and drying curves, respectively; MCSA, method of constant-saturation absorption; MCPA, method of constant-pressure head absorption.

only a traditional horizontal absorption experiment (Bruce and Klute, 1956) and a constant head method for measuring $K_{s}$ (Klute and Dirksen, 1986) are required. During the absorption process, we only need to record the visually observable water table change in a Marriott bottle and the wetting front advance versus time. The variables $d$ and $s$ can be obtained by fitting Eqs. (9) and (10) to the observed wetting front advance and the cumulative infiltration volume versus the square root of infiltration time, respectively. $A$ is calculated from $s$ divided by $d$, and $a$ is calculated via Eq. (8). Then, the soil-water diffusivity parameters $L$ and $D_{\mathrm{s}}$ can be estimated by Eqs. (6) and (7) in MCSA or Eqs. (6) and (20) in MCPA, respectively. The SWRC parameters $n$ and $h_{\mathrm{d}}$ are estimated by Eqs. (4) and (5), respectively, in the old method (MCSA), whereas Eqs. (4) and (19) are employed in the improved method (MCPA).
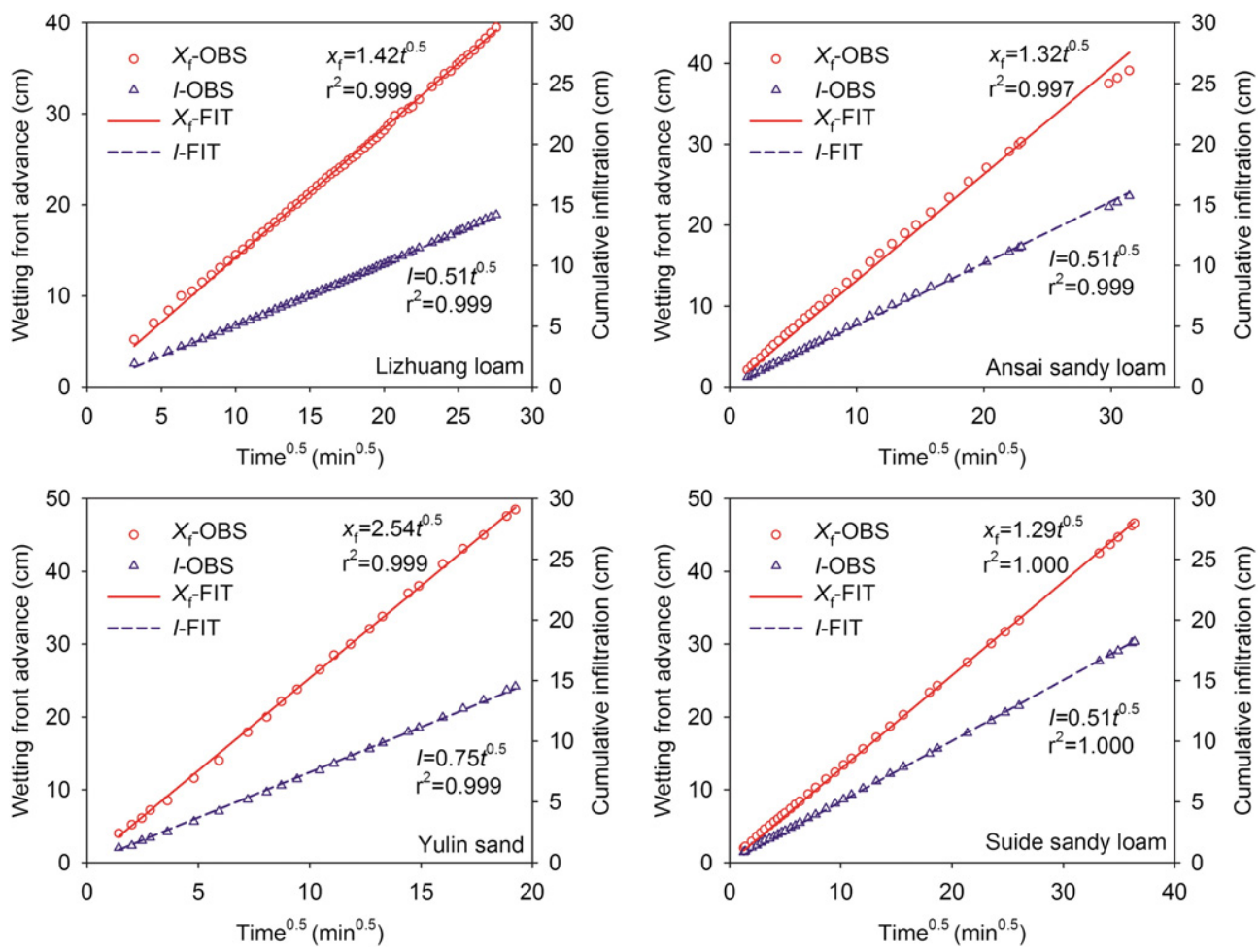

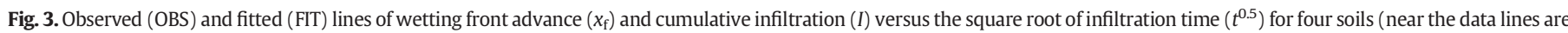
the corresponding results of linear regressions, where $r^{2}$ is the determination coefficient). 
Because soil-water diffusivity data and SWRC data are not available for all 20 of the soils in Table 1, different soils were used to test different methods. The observed soil-water diffusivity curves of 14 soils (No. 1-4 and 11-20 in Table 1) were used to test the reliability of MCSA and MCPA in determining soil-water diffusivity. The determination coefficient $r^{2}$, the slope and the offset of linear regression were chosen to evaluate the agreement between the predicted and observed soil-water diffusivity curves. The estimated values of $D_{\mathrm{s}}$ and $L$ are listed in Table 2. The SWRCs of 10 soils (No.1-10 in Table 1 ) predicted by the estimated BC model parameters (Table 2) of MCSA and MCPA were tested by comparing the measured wetting and drying curves of the SWRCs, respectively. Root mean square error (RMSE) was used to evaluate the deviation of the estimated SWRCs from the observed SWRCs. In addition, we simulated horizontal absorption processes under the same initial and boundary conditions as the experiments above, using HYDRUS1D (Šimůnek et al., 2005) with the estimated BC model parameters in Table 2 . The simulated cumulative absorption curves were compared with the observed curves to further verify MCSA and MCPA.

\section{Results and discussion}

Apart from $K_{\mathrm{s}}, \theta_{\mathrm{s}}$ and $\theta_{\mathrm{i}}$, the estimated BC model parameters depend on $s$ and $d$, which are the only two parameters in Eqs. (4)-(7) and (8). It was necessary to obtain $s$ and $d$ from horizontal absorption experiments. As examples, Fig. 3 shows the observed data of the wetting front advance and the cumulative infiltration versus the square root of infiltration time, as well as the results of fitting Eqs. (9) and (10) to those data for four soils (Lizhuang loam soil, Ansai sandy loam, Yulin sand, and Suide sandy loam). Fig. 3 shows that $r^{2}$ was greater than 0.99 for all linear regressions, indicating strong linear relationships between $x_{\mathrm{f}}$ or $I$ and $t^{0.5}$. The slope of the regression line is $d$ for $x_{\mathrm{f}}$ versus $t^{0.5}$ and $s$ for $I$ versus $t^{0.5}$.

Fig. 4 shows the soil-water diffusivity curves predicted by Eq. (3) with the estimated parameters in Table 2, as well as the measured curves by the Bruce and Klute method for 14 soils. Clearly, MCPA yields lower estimates of soil-water diffusivity than MCSA for all soils. The MCPA-predicted soil-water diffusivities are also lower than most
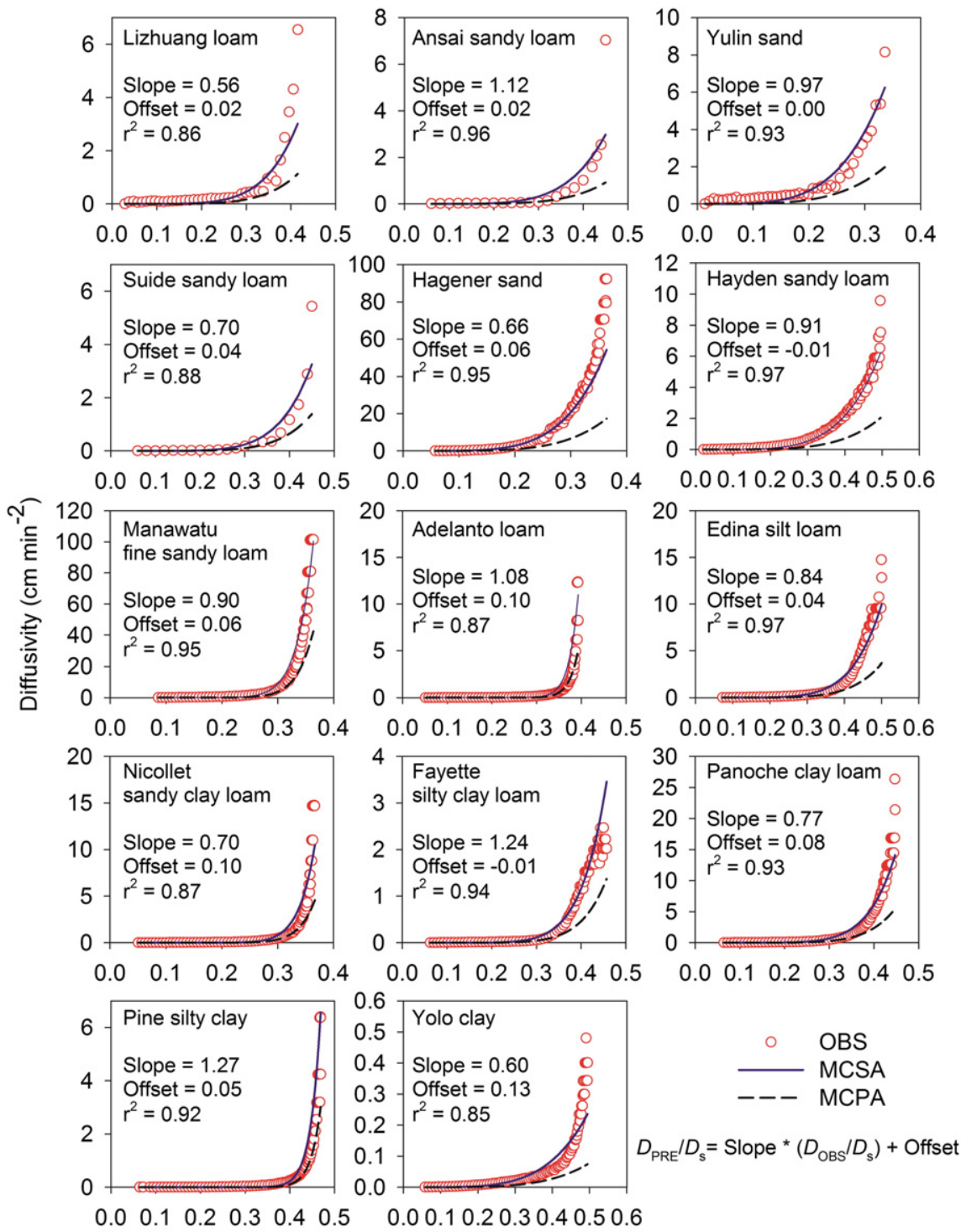

Soil moisture content $\left(\mathrm{cm}^{3} \mathrm{~cm}^{-3}\right)$

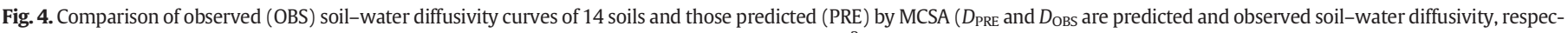

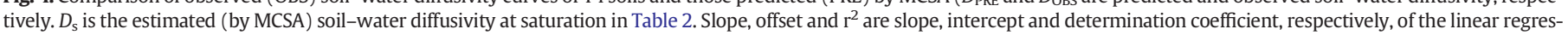
sion between the estimated and observed soil-water diffusivity curves). 
measured values, especially in the near-saturated section. In contrast, the curves predicted by MCSA are in good agreement with the measured curves for the 14 test soils. The results for 14 test soils of the linear regression between the soil-water diffusivity curves estimated by MCSA and the observed soil-water diffusivity curves for 14 test soils are also listed in Fig. 4. The results indicate that the minimum $\mathrm{r}^{2}$ is 0.85 , and most values of $r^{2}$ are greater than 0.90 . All of the offsets of 14 test soils are less than $15 \%$ of the estimated $D_{s}$. The slopes of only 3 out of 14 soils (Lizhuang loam soil, Hagener sand and Yolo clay) deviate more than 30\% from 1. Clearly, few points near saturation on the curves should be responsible for this substantial deviation of slopes from 1. Although there are deviations of predicted from measured values at some points (Fig. 4), especially near saturation, these can be explained. The soil moisture profiles for calculating soil-water diffusivity are composed of discrete measurement points and are thus not sufficiently smooth for direct use in the Bruce and Klute method. Normally, techniques such as manual regulation and numerical smoothing are required to smooth the curves (Klute and Dirksen, 1986), but no standard objective approach is currently available. As a result, smoothed curves may lose the actual shapes of the soil moisture profiles. Maximum errors occur near saturation, because soil-water diffusivity is the most sensitive to soil moisture change with distance in this range. Another possibility is that the actual soil-water diffusivity curves do not exactly obey the power-function (Eq. (3)).

Fig. 5 shows estimated SWRCs by the MCSA and MCPA methods, for comparison with the measured data of 10 soils in the wetting and drying processes. As shown in the Fig. 5, MCSA predicted higher soil moisture contents than MCPA for the same estimated values of $n$, but it yielded higher estimates of $h_{\mathrm{d}}$ (Table 2). Whether for wetting or drying curves, RMSEs of the curves predicted by MCPA are smaller than those of MCSA, except for four soil drying curves (Ansai sandy loam, Suide sandy loam, Shenmu sand $\left(R_{\mathrm{m}}=30 \%\right)$ and Shenmu sand $\left(R_{\mathrm{m}}=\right.$ $40 \%)$ ). For MCPA, eight of the ten predicted SWRCs agree well with the measured ones (Fig. 5). MCPA slightly overestimated the suction
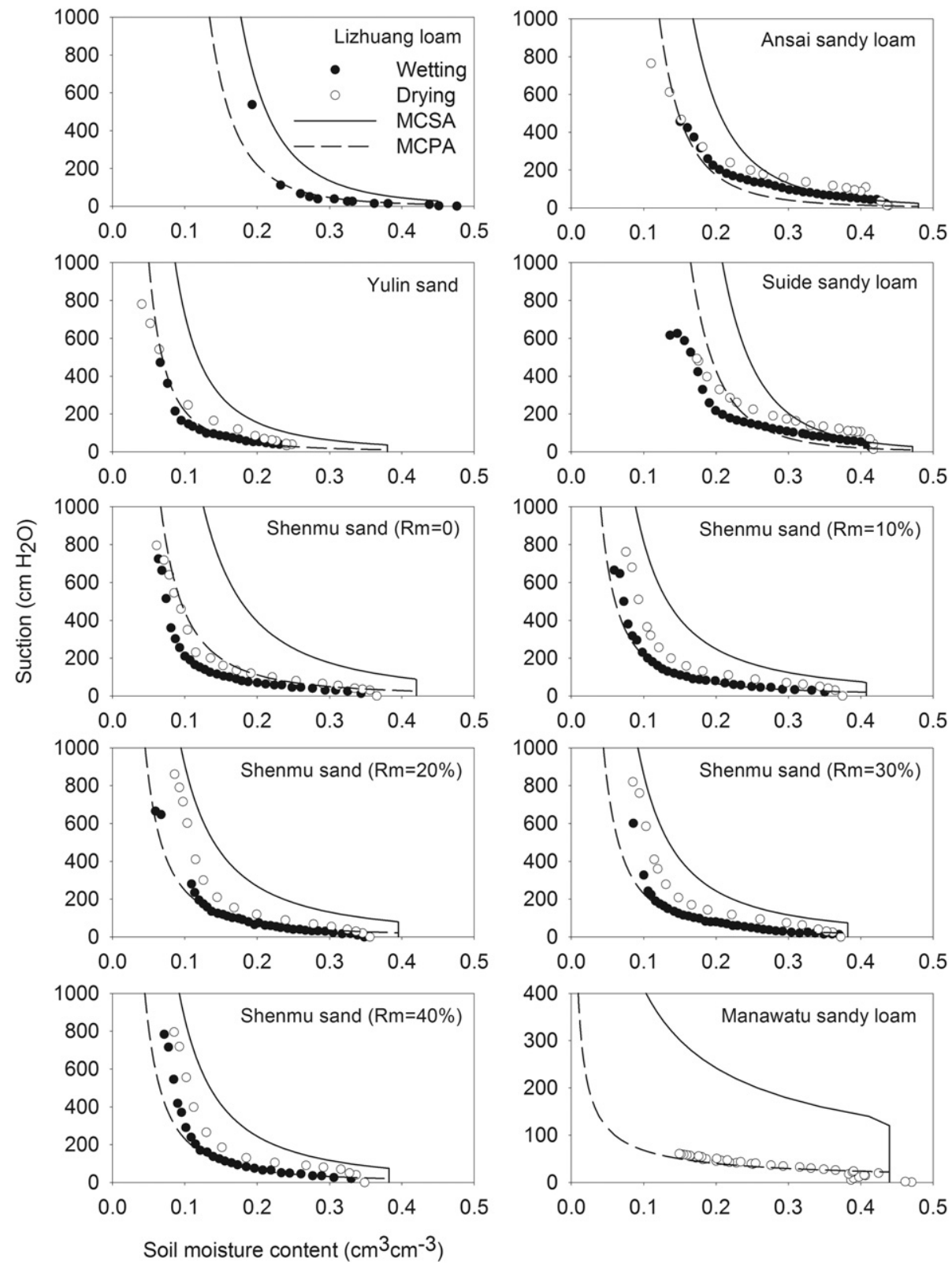

Fig. 5. Comparison of observed (Wetting: wetting curves; Drying: drying curves) and predicted (by MCSA and MCPA) SWRCs of 10 soils. 
of the Ansai and Suide soils at low moisture content and underestimated the suction at high moisture content, but the predicted SWRCs are generally consistent with the measured curves. Additionally, it is seen that the SWRCs predicted by MCPA are closer to the wetting curves than the drying curves, because the method was based on horizontal infiltration, which is a wetting process. RMSEs between SWRCs predicted by MCPA and measured wetting curves are smaller than $0.07 \mathrm{~cm}^{3} \mathrm{~cm}^{-3}$ and even $0.04 \mathrm{~cm}^{3} \mathrm{~cm}^{-3}$ for most test soils, which are also smaller than those between the predicted SWRCs and the measured drying curves (Table 2). Therefore, the estimated SWRCs are sensitive enough to hysteresis effects, which implies that the estimate errors of SWRCs by MCPA are smaller than or at most comparable to those induced by the hysteresis effect. Because the hysteresis effect of a SWRC is usually neglected in soil-water movement simulations and because commonly-used SWRC data are measured in the drying process, soilwater movement simulations by MCPA are expected to be not worse when using the estimated soil hydraulic properties.

Because the MCSA and MCPA methods were derived based on approximations of horizontal soil-water infiltration processes, it is necessary to test whether soil hydraulic properties predicted by these methods can be used for accurate simulations of soil-water movement processes using numerical solutions. Fig. 6 shows comparisons between measured and simulated horizontal one-dimensional cumulative absorptions of soils No. 1-9 in Table 2 using the HYDRUS-1D software (Šimůnek et al., 2005) with soil hydraulic parameters estimated by MCSA and MCPA. Fig. 6 shows the relationship between the cumulative absorption curves simulated by HYDRUS-1D and the parameters estimated by MCPA; the observed curves follow the 1:1 line closely. However, HYDRUS-1D with the MCSA-estimated parameters greatly overestimated the cumulative absorption volume. The average relative error of the simulated cumulative absorption by HYDRUS-1D reached $82 \%$ when MCSA was used to estimate the BC model parameters.

In Ma et al. (2009), the MCSA method was tested only by numerical absorption experiments with constant-saturation boundary conditions, which is equivalent to exerting a negative pressure head of $-h_{\mathrm{d}}$ on the inlet boundary. When strict experimental conditions are satisfied, MCSA can also produce accurate estimations, as revealed in Ma et al. (2009). Unfortunately, it is difficult to conduct such experiments under the condition of $h_{\mathrm{p}}=-h_{\mathrm{d}}$, because $h_{\mathrm{d}}$ is one of the parameters to be estimated. In addition, $h_{\mathrm{p}}$ is very near zero in most actual horizontal absorption experiments. This is the reason why soil suctions or moisture contents were overestimated when the experimental data were used instead of the numerically simulated infiltration data. In the MCPA method, inlet

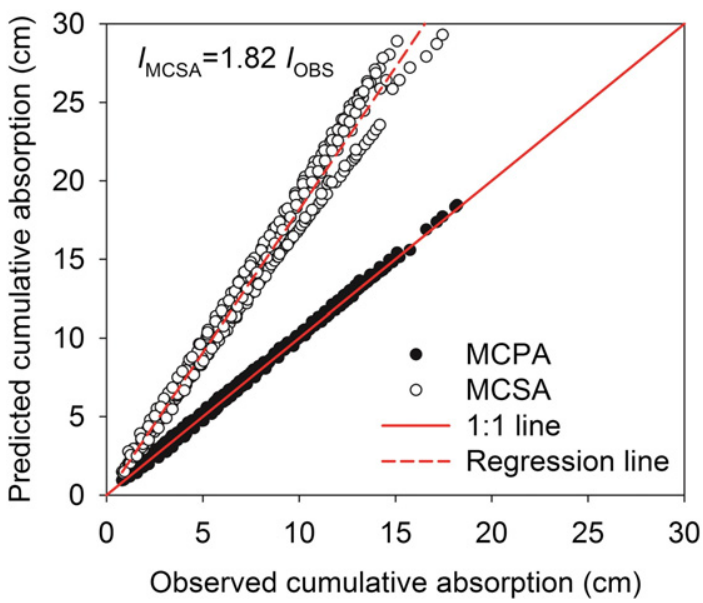

Fig. 6. Comparison of observed and predicted cumulative infiltration curves of soils No. $1-9$, using the HYDRUS-1D software with BC model parameters estimated by MCSA and MCPA. boundary conditions $\left(h_{\mathrm{p}}=0\right)$ closer to the normal horizontal absorption experiments were considered. Clearly, this change in inlet boundary conditions greatly improved the accuracy of SWRCs estimated from experimental data. Thus, MCPA is more accurate in practice than MCSA for estimating SWRCs.

Considering the inherent problem in the BC model, it is not surprising that MCSA or MCPA only succeeded in estimating one of either soilwater diffusivity or SWRC but failed to accurately estimate both of them. In the $\mathrm{BC}$ model, unsaturated soil hydraulic conductivity and soil-water diffusivity are deduced from the SWRC based on capillary theory (Burdine, 1953). The theoretical adequacy of assumptions behind the capillary theory is not strong enough to guarantee the practical usability of the BC model (Vogel and Cislerova, 1988), which implies that it is difficult to simultaneously obtain accurate soil hydraulic properties (i.e., SWRC, unsaturated hydraulic conductivity and soil-water diffusivity) by the $\mathrm{BC}$ model in some cases. Thus, it is possible that the type of soil hydraulic properties used when solving Richards equation determines which type of soil hydraulic properties the approximate solution is more sensitive to. The approximate solution to Richards equation in MCSA was obtained by using soil-water diffusivity (Ma et al., 2009), which is similar to that in the Bruce and Klute method (Bruce and Klute, 1956). In MCPA, Richards equation was solved by using SWRC. Therefore, apart from the inlet boundary problem aforementioned, the types of soil hydraulic properties used in approximate solutions make MCSA more appropriate for determining soil-water diffusivity and make MCPA more accurate for estimating SWRC.

Measurement errors are inevitable during experiments. Compared with other properties, it is easy to make accurate measurements of $\theta_{\mathrm{s}}$ and $\theta_{\mathrm{i}}$. Errors mainly come from estimated or measured $\theta_{\mathrm{r}}, A$ and $K_{\mathrm{s}}$. In Ma et al. (2009), sensitivity of the estimated BC model parameters to $\theta_{\mathrm{r}}$ and $A$ was discussed. The estimated $n$ and $h_{\mathrm{d}}$ were very sensitive to $A$, the error in which was mainly induced by inaccurate measurement of water volume change in the water room at the water inlet, so cumulative infiltration was not well corrected. An approach used in the present research to overcome this problem was to attribute the nonzero intercept of linear regression ( $I$ versus $x_{\mathrm{f}}$ ) to inappropriate correction of cumulative absorption by the water volume in the water room (Fig. 1).

As shown in Ma et al. (2009), $n$ and $h_{\mathrm{d}}$ were not sensitive to $\theta_{\mathrm{r}}$ because the latter normally varies within a very narrow range. Although satisfactory determination of $\theta_{\mathrm{r}}$ may improve the estimations of $\mathrm{BC}$ model parameters, such improvements would be limited, especially for coarse-texture soils. It is customary to take soil moisture content at a pressure of $-1500 \mathrm{kPa}$ as an estimate or the upper bound of real $\theta_{\mathrm{r}}$ (van Genuchten, 1980), but measurement requires expensive apparatus and is time-consuming. An alternative approach is to use pedotransfer functions to estimate $\theta_{\mathrm{r}}$ from other soil properties (e.g., soil texture, bulk density, and organic matter content) (Gupta and Larson, 1979; Rajkai et al., 2004; Rawls and Brakensiek, 1982; Saxton and Rawls, 2006). A limitation of using such a function is that it usually only applies to a specific region or soil type (Wosten et al., 2001). Thus, using a specific pedotransfer function for a region may achieve a better estimate of $\theta_{\mathrm{r}}$. In this research, we adopted the simplest method, assuming $\theta_{\mathrm{r}}$ equal to zero, for the convenience of practical applications. The results indicate that the improved method of MCPA still estimated soil hydraulic properties that were consistent with those observed.

From Eq. (19), it was found that the estimated $h_{\mathrm{d}}$ increases linearly with $h_{\mathrm{p}}$. However, in practice, knowing the accurate water pressure head at the inlet is not difficult. It is impossible that an error of only one or two centimeters for the water pressure head produces large errors. The maximum estimated error of $h_{\mathrm{d}}$ may originate from the measurement of $K_{\mathrm{s}}$, which is inversely proportional to $h_{\mathrm{d}}$ as shown by Eq. (19). $K_{\mathrm{s}}$ is one of the soil properties with strong in situ variations (van der Keur and Iversen, 2006). Variation of one order of magnitude is normal for $K_{\mathrm{s}}$ between different locations in one field. For disturbed soils, the variation of $K_{\mathrm{s}}$ may be less than that in situ, but it is also 
possible that soil columns were not packed very uniformly. The best method is to determine $K_{\mathrm{s}}$ using the same column as the absorption experiment, which we did for the Shenmu sandy soils. This may be the reason why MCPA predicted the SWRCs of Shenmu sandy soils more accurately than those of the first four soils (Fig. 5).

\section{Conclusions}

Using simple apparatuses and few measurements to make rapid and accurate estimations of soil hydraulic properties is one of the main objectives for soil physicists and hydrologists. Indirect or inverse methods based on approximate solutions to simple soil-water movement processes represent a promising research direction. An approximate solution to constant-saturation absorption and an approach (MCSA) based on it were proposed by Ma et al. (2009) to estimate Brooks-Corey hydraulic model parameters from horizontal absorption experiments. In this work, absorption experiments and measured soil hydraulic properties for 20 soil samples were used to test the method. The results indicate that MCSA-predicted unsaturated soil-water diffusivity curves are in good agreement with those measured by the Bruce and Klute method, but MCSA overestimated soil suctions or soil moisture contents for all test soils. A new method (MCPA) was developed to improve estimation of the SWRCs. With MCPA, the overestimation of air-entry suction in MCSA was overcome and SWRCs more consistent with measured curves were obtained. Using the SWRCs estimated by MCPA, cumulative infiltration curves simulated by HYDRUS-1D are in strong agreement with observed curves. However, for the possible inherent problem in the BC model, MCPA underestimated soil-water diffusivity. Thus, MCSA is suggested if unsaturated soil-water diffusivity curves comparable to those measured by the Bruce and Klute method are required, whereas MCPA is better if SWRCs are of greater concern. All of the measurements required by these methods are rapid and easy to perform, and the apparatus for the experiments are simple and low cost. Compared with other traditional direct and indirect methods, the method proposed herein is accurate and convenient to use in laboratories for measuring the hydraulic properties of disturbed soils. This method is also promising as a basis for developing even simpler approaches to estimating soil hydraulic properties of undisturbed soils in situ. It should be noted that the methods (MCSA and MCPA) are limited to initially dry homogeneous soils. Initially high soil moisture contents or uneven soil moisture distributions will increase the errors of estimated soil hydraulic properties. Heterogeneity of soil texture will also increase the uncertainty associated with observing and determining wetting front advances, and thus it would lower the accuracy of estimated soil hydraulic properties.

\section{Acknowledgments}

This work was supported by the National Natural Science Foundation of China (No. 50909090), the National Basic Research Program of China (No. 2011CB100506), the Science and Technology Service Network Initiative of the Chinese Academy of Sciences (No. KFJ-EWSTS-055) and the National Key Technology Research and Development Program (No. 2012BAD05B02).

\section{References}

Brooks, R.H., Corey, A.T., 1964. Hydraulic Properties of Porous Media. Hydrol. Colorado State University, Fort Collins, pp. 3-27.

Bruce, R.R., Klute, A., 1956. The measurement of soil moisture diffusivity. Soil Sci. Soc. Am. Proc. 20, 458-462.

Burdine, N.T., 1953. Relative permeability calculations from pore size distribution data. Trans. Am. Inst. Min. Metall. Eng. 198, 71-78.

Clothier, B.E., Scotter, D.R., 1982. Constant-flux infiltration from a hemispherical cavity. Soil Sci. Soc. Am. J. 46, 696-700.

Clothier, B.E., Scotter, D.R., Green, A.E., 1983. Diffusivity and one-dimensional absorption experiments. Soil Sci. Soc. Am. J. 47, 641-644.
Dane, J.H., Puckett, W.E., 1992. Field soil hydraulic properties based on physical and mineralogical information. In: van Genuchten, M.T., Leij, F.J. (Eds.), Proc. Int. Worksh. Indirect methods for estimating the hydraulic properties of unsaturated soils. Univ. of California, Riverside, pp. 389-403.

Durner, W., Lipsius, K., 2005. Determining soil hydraulic properties. In: Anderson, M.G. (Ed.), Encyclopedia of Hydrological Sciences. John Wiley \& Sons, Ltd.

Evangelides, C., Arampatzis, G., Tzimopoulos, C., 2010. Estimation of soil moisture profile and diffusivity using simple laboratory procedures. Soil Sci. 175, 118-127. http://dx. doi.org/10.1097/Ss.0b013e3181d53bb6.

Gee, G.W., Or, D., 2002. Pipette method: particle-size analysis. In: Dane, J.H., Topp, G.C. (Eds.), Methods of soil analysis Part 4 Physical methods. Soil Science Society of America, Inc., Madison, Wisconsin, USA, pp. 272-278.

Gupta, S.C., Larson, W.E., 1979. Estimating soil-water retention characteristics from particle-size distribution, organic-matter percent, and bulk-density. Water Resour. Res. 15, 1633-1635. http://dx.doi.org/10.1029/Wr015i006p01633.

Haverkamp, R., Parlange, J.Y., Starr, J.L., Schmitz, G., Fuentes, C., 1990. Infiltration under ponded conditions: 3. A predictive equation based on physical parameters. Soil Sci. 149, 292-300. http://dx.doi.org/10.1097/00010694-199005000-00006.

Jackson, R.D., 1963. Porosity and soil-water diffusivity relations. Soil Sci. Soc. Am. J. 27 123-126. http://dx.doi.org/10.2136/sssaj1963.03615995002700020011×.

Klute, A., Dirksen, C., 1986. Hydraulic conductivity and diffusivity: laboratory methods. In: Klute, A. (Ed.), Methods of soil analysis. Part 1, 2nd ed. Agron. Monogr. 9. ASA and SSSA, Madison, WI, pp. 716-719.

Londra, P.A., Valiantzas, J.D., 2011. Soil-water diffusivity determination using a new twopoint outflow method. Soil Sci. Soc. Am. J. 75, 1343-1346. http://dx.doi.org/10.2136/ sssaj2010.0448.

Ma, D.H., Shao, M.A., 2008. Simulating infiltration into stony soils with a dual-porosity model. Eur. J. Soil Sci. 59, 950-959.

Ma, D.H., Wang, Q.J., Shao, M.A., 2009. Analytical method for estimating soil hydraulic parameters from horizontal absorption. Soil Sci. Soc. Am. J. 73, 727-736. http://dx.doi. org/10.2136/sssaj2008.0050.

Ma, D.H., Shao, M.A., Zhang, J.B., Wang, Q.J., 2010. Validation of an analytical method for determining soil hydraulic properties of stony soils using experimental data. Geoderma 159, 262-269.

Mcbride, J.F., Horton, R., 1985. An empirical-function to describe measured water distributions from horizontal infiltration experiments. Water Resour. Res. 21, 1539-1544. http://dx.doi.org/10.1029/Wr021i010p01539.

Morelsey, H.J., Khanji, J., 1974. Derivation of an equation of infiltration. Water Resour. Res. 10, 795-800. http://dx.doi.org/10.1029/WR010i004p00795.

Nofziger, D.L., 1978. Errors in gamma-ray measurements of water-content and bulkdensity in nonuniform soils. Soil Sci. Soc. Am. J. 42, 845-850.

Philip, J.R., 1958. The theory of infiltration: 7. Soil Sci. 85, 333-337.

Philip, J.R., 1973. On solving the unsaturated flow equation: 1 . The flux-concentration relation. Soil Sci. 116, 328-335.

Rajkai, K., Kabos, S., van Genuchten, M.T., 2004. Estimating the water retention curve from soil properties: comparison of linear, nonlinear and concomitant variable methods. Soil Tillage Res. 79, 145-152. http://dx.doi.org/10.1016/j.still. 2004.07.003.

Rawls, W.J., Brakensiek, D.L., 1982. Estimating soil-water retention from soil properties J. Irrig. Drain. Eng. ASCE 108, 166-171.

Reichardt, K., Nielsen, D.R., Biggar, J.W., 1972. Scaling of horizontal infiltration into homogeneous soils. Soil Sci. Soc. Am. Proc. 36, 241-245.

Richards, L.A., 1931. Capillary conduction of liquids through porous mediums. Physics 1, 318-333.

Saxton, K.E., Rawls, W.J., 2006. Soil-water characteristic estimates by texture and organic matter for hydrologic solutions. Soil Sci. Soc. Am. J. 70, 1569-1578.

Selim, H.M., Kirkham, D., Amemiya, M., 1970. A comparison of two methods for determining soil-water diffusivity. Soil Sci. Soc. Am. Proc. 34, 14-18.

Shao, M.A., Horton, R., 1996. Soil-water diffusivity determination by general similarity theory. Soil Sci. 161, 727-734.

Shao, M.A., Horton, R., 1998. Integral method for estimating soil hydraulic properties. Soil Sci. Soc. Am. J. 62, 585-592.

Šimůnek, J., van Genuchten, M.T., Šejna, M., 2005. The HYDRUS-1D Software Package for Simulating the Movement of Water, Heat, and Multiple Solutes in Variably Saturated Media. Department of Environmental Sciences,University of California Riverside, Riverside, California, USA.

Stewart, R.D., Rupp, D.E., Abou Najm, M.R., Selker, J.S., 2013. Modeling effect of initial soil moisture on sorptivity and infiltration. Water Resour. Res. 49, 7037-7047. http://dx doi.org/10.1002/Wrcr.20508.

Valiantzas, J.D., Londra, P.A., 2008. Direct determination of the Brooks-Corey hydraulic functions by fitting an extended power function to the outflow method data. J. Hydrol. 362, 128-133. http://dx.doi.org/10.1016/j.jhydrol.2008.08.021.

Valiantzas, J.D., Londra, P.A., 2012. Simplified equations for the determination of the hydraulic properties of horticultural substrates by one-step outflow experiments. J. Plant Nutr. Soil Sci. 175, 49-52.

van Dam, J.C., Stricker, J.N.M., Droogers, P., 1992. Inverse method for determining soil hydraulic functions from one-step outflow experiments. Soil Sci. Soc. Am. J. 56 1042-1050.

van der Keur, P., Iversen, B.V., 2006. Uncertainty in soil physical data at river basin scale a review. Hydrol. Earth Syst. Sci. 10, 889-902.

van Genuchten, M.T., 1980. A closed-form equation for predicting the hydraulic conductivity of unsaturated soils. Soil Sci. Soc. Am. J. 44, 892-898.

van Genuchten, M.T., 1992. On estimating the hydraulic properties of unsaturated soils In: van Genuchten, M.T., Leij, F.J. (Eds.), Proc. Int. Worksh. Indirect methods for estimating the hydraulic properties of unsaturated soils. Univ. of California, Riverside, pp. 1-14. 
Vogel, T., Cislerova, M., 1988. On the reliability of unsaturated hydraulic conductivity calculated from the moisture retention curve. Transp. Porous Media 3, 1-15.

Wang, Q.J., Horton, R., Shao, M.A., 2002. Horizontal infiltration method for determining Brooks-Corey model parameters. Soil Sci. Soc. Am. J. 66, 1733-1739.

Wang, Q.J., Shao, M.A., Horton, R., 2004. A simple method for estimating water diffusivity of unsaturated soils. Soil Sci. Soc. Am. J. 68, 713-718.

Whisler, F.D., Klute, A., Peters, D.B., 1968. Soil-water diffusivity from horizontal infiltration. Soil Sci. Soc. Am. Proc. 32, 6-11.
White, I., Sully, M.J., 1987. Macroscopic and microscopic capillary length and time scales from field infiltration. Water Resour. Res. 23, 1514-1522. http://dx.doi.org/10.1029/ Wr023i008p01514.

Wosten, J.H.M., Pachepsky, Y.A., Rawls, W.J., 2001. Pedotransfer functions: bridging the gap between available basic soil data and missing soil hydraulic characteristics. J. Hydrol. 251, 123-150. 